\author{
RAJMUND MOLSKI \\ ORCID: 0000-0001-5019-5692 \\ Uniwersytet Szczeciński \\ rajmund.molski@usz.edu.pl
}

\title{
Prawo antymonopolowe a polityka wspierania rozwoju małych i średnich przedsiębiorców
}

\begin{abstract}
Abstrakt: Celem artykułu jest pogłębienie nader wątłej wciąż refleksji naukowej nad rolą prawa antymonopolowego w polityce wspierania rozwoju małych i średnich przedsiębiorców (MŚP). W pierwszej kolejności przedstawiono syntetyczny obraz ewolucji i aktualnego stanu poglądów w kwestii ochrony MŚP jako celu prawa antymonopolowego. Następnie ukazano specyfikę definicji MŚP w prawie antymonopolowym. Kolejną część artykułu poświęcono wpływowi prawa antymonopolowego na rozwój MŚP, rozpatrywanemu z perspektywy publicznego i prywatnego egzekwowania tego prawa, z uwzględnieniem dwoistej sytuacji MŚP jako jego beneficjentów i naruszycieli. W podsumowaniu wskazano, że choć prawo antymonopolowe i polityka wspierania rozwoju MŚP powinny ze sobą współgrać, to nie zawsze tak się dzieje. Za godne aprobaty uznano stanowisko, że prawo antymonopolowe nie powinno w wyjątkowy sposób chronić przedsiębiorców tylko dlatego, że są mali i nie są w stanie sprostać konkurencji ze strony większych rywali, zwłaszcza jeśli miałoby się to odbywać kosztem konsumentów.
\end{abstract}

Słowa kluczowe: prawo antymonopolowe, mali i średni przedsiębiorcy, polityka gospodarcza.

Mali i średni przedsiębiorcy są siłą napędową gospodarki i pełnią ważne funkcje społeczne, ale wszyscy jesteśmy konsumentami, i nikt nie lubi płacić wyższych cen.

\section{Wprowadzenie}

Jak głosi słynna maksyma Cycerona, ,początki wszystkich rzeczy są małe” („omnium enim rerum principia parva sunt”) ${ }^{1}$. Małe jest też (czasami) piękne, rów-

1 Marcus Tulius Cicero, De finibus bonorum et malorum, Oxford 1998, s. 203. 
nież w kontekście gospodarczym² ${ }^{2}$. Swoistą egzemplifikacją tych myśli może być fenomen rozwoju małych i średnich przedsiębiorców (MŚP) i jego szczególne znaczenie w kształtowaniu sytuacji społeczno-gospodarczej współczesnych państw. Doprawdy trudno przecenić wkład tej kategorii przedsiębiorców w pomnażanie dochodów budżetowych, zwiększanie zatrudnienia, innowacyjności i konkurencyjności, zaopatrywanie $\mathrm{w}$ towary i usługi lokalnych społeczności czy pobudzanie ducha przedsiębiorczości. Wszelako z powodu niewielkich rozmiarów przedsiębiorcy ci borykają się ze specyficznymi barierami rozwoju. Zdolność MŚP do wypełniania ich roli w osiąganiu różnych celów gospodarczych i społecznych jest też $\mathrm{w}$ dużej mierze determinowana otoczeniem regulacyjnym i polityką państwa. Jednym z kluczowych elementów tej polityki stało się współcześnie przeciwdziałanie barierom wzrostu MŚP i jego wspieranie. Niewątpliwie doniosłą rolę w tym względzie ma do odegrania prawo antymonopolowe jako kluczowy instrument polityki konkurencji. Tymczasem, co może zaskakiwać, do niedawna kwestia ta nie była przedmiotem szerszego zainteresowania teorii i praktyki prawa antymonopolowego, czy ogólniej - publicznego prawa gospodarczego. W polskim piśmiennictwie wciąż trudno doszukać się nawet przyczynkowych opracowań na ten temat. Niniejszy artykuł ma na celu zaradzenie, choćby w skromnym zakresie, tej anomalii.

\section{Ochrona MŚP jako cel prawa antymonopolowego}

Teoretycy i praktycy prawa antymonopolowego są notorycznie podzieleni w kwestii celów, jakie ma ono realizować3. Niewątpliwie jednak w ich wielowarstwowej strukturze pojawia się wzgląd na ochronę MŚP. Stosunkowo rzadko cel ten wyrażany jest expressis verbis $\mathrm{w}$ prawie stanowionym (jak na przykład w Indonezji, Kanadzie czy RPA ${ }^{4}$ ). Znacznie częściej daje się on wyinterpretować na

2 Nawiązanie do głośnego niegdyś przesłania E.F. Schumachera, które wyraża się w tytule jego wpływowej książki Małe jest piękne. Ekonomia z założeniem, że człowiek się liczy, Warszawa 2013.

3 Zob. The Goals of Competition Law, red. D. Zimmer, Cheltenham 2012; European Competition Law Annual 1997: The Objectives of Competition Policy, red. C.D. Ehlermann, L.L. Laudati, Oxford 1998; R. Molski, Prawo antymonopolowe w obliczu globalizacji. Kierunki rozwoju, Szczecin-Bydgoszcz 2007, s. 74.

${ }^{4}$ Indonezyjska ustawa z 1999 roku o zakazie praktyk monopolistycznych i nieuczciwej konkurencji gospodarczej proklamuje, że jednym z jej celów jest „zapewnienie równych warunków rozwoju dla dużych, średnich i małych przedsiębiorców". Z kolei kanadyjska ustawa z 1985 roku o konkurencji deklaruje, że jej celem jest między innymi „,zapewnienie, aby mali i średni przedsiębiorcy mieli sprawiedliwe szanse partycypacji w kanadyjskiej gospodarce". Podobnie południowoafrykańska ustawa z 1998 roku o konkurencji wśród celów tej regulacji wymienia „zapewnienie małym i średnim przedsiębiorcom sprawiedliwych szans udziału w gospodarce”. Zob. E.M. Fox, Equality, Discrimination, and Competition Law: Lessons from and for South Africa and Indonesia, Harvard 
drodze wykładni przepisów prawa antymonopolowego (na przykład w prawie konkurencji UE ochronę MŚP uznano za cel tego prawa w ramach wykładni art. 102 TFUE zakazującego nadużywania pozycji dominującej, a także wytycznych Komisji Europejskiej dotyczących porozumień o mniejszym znaczeniu — de minimis ${ }^{5}$ ).

Budzący liczne spory i kontrowersje cel ochrony MŚP za pomocą instrumentów prawa antymonopolowego lokuje się współcześnie zazwyczaj w tak zwanej szarej strefie na pograniczu celów tego prawa uznawanych za podstawowe i definitywne (na przykład ochrona konkurencji podyktowana względami efektywności gospodarczej i maksymalizacją dobrobytu konsumentów) oraz akcesoryjne i pośrednie, tak zwanych celów interesu publicznego (na przykład uczciwość konkurowania czy dyspersja władzy gospodarczej).

Co może zaskakiwać, u zarania dziejów współczesnego prawa antymonopolowego ochronę MŚP traktowano wręcz jako jego cel główny i ostateczny. Przez pierwsze cztery dekady obowiązywania amerykańskiego prawa antytrustowego, uznawanego za pierwowzór nowoczesnego prawa antymonopolowego, Sąd Najwyższy (SN) USA przyjmował, że celem tego prawa jest przede wszystkim ochrona drobnych producentów i handlowców przed eksploatacją ze strony ich większych konkurentów czy kontrahentów ${ }^{6}$. Już wówczas jednak okazało się, jak wysoce problematyczne mogą być kontradykcje między protekcją małych przedsiębiorców a dobrobytem konsumentów i efektywnością gospodarczą ${ }^{7}$. W skrócie rzecz ujmując, konsumenci czerpią korzyści z niskich cen, wysokiej jakości i szerokiego asortymentu towarów i usług, tymczasem przedsiębiorcy oferujący te korzyści nieuchronnie godzą w interesy konkurentów, zazwyczaj mniejszych lub stosujących starsze technologie. Znamienne, że w obliczu kolizji między celami ochrony małych przedsiębiorców i maksymalizacji dobrobytu konsumentów czy efektywności SN USA dawał początkowo prymat temu pierwszemu. Dopuszczał na przykład uznanie za naruszenie reguł konkurencji praktyki rynkowej, która skutkuje przejściową czy nawet permanentną obniżką cen ${ }^{8}$. Wprawdzie od lat siedemdziesiątych XX wieku amerykańska judykatura radykalnie odeszła od tej

Int'1 L.J. 41, 2000, s. 579; M. Trebilcock et al., The Law and Economics of Canadian Competition Policy, Toronto 2002, s. 39.

5 L. Parret, Shouldn't We Know What We Are Protecting? Yes We Should! A Plea for a Solid and Comprehensive Debate About the Objectives of EU Competition Law and Policy, European Competition J. 6, 2010, s. 353.

6 S. Vaheesan, The Evolving Populisms of Antitrust, Nebraska L.Rev. 93, 2014, s. 372; H. Hovenkamp, Federal Antitrust Policy: The Law of Competition and Its Practice, St. Paul 1999, s. 49; J.D. Wright et al., Requiem for a Paradox: The Dubious Rise and Inevitable Fall of Hipster Antitrust, Arizona State L.J. 51, 2019, s. 300.

${ }^{7}$ H. Hovenkamp, Whatever Did Happen to the Antitrust Movement?, Notre Dame L.Rev. 94, 2019, s. 585.

8 Zob. wyroki SN USA w sprawach: Fashion Originators' Guild of America, Inc. v. Federal Trade Commission, 312 U.S. 457, 467 (1941); Utah Pie Co. v. Cont'l Baking Co., 386 U.S. 685 (1967); Brown Shoe C. v. United States, 370 U.S. 294, 344 (1962). 
(tak zwanej populistycznej) linii orzeczniczej, uznając, że właściwym celem prawa antytrustowego jest ochrona konsumentów, a nie konkurentów, ale wbrew dość powszechnemu przekonaniu nie oznacza to zupełnej eliminacji amerykańskiego prawa antytrustowego celu, jakim jest ochrona MŚP. Po pierwsze, w sprawach antykonkurencyjnych praktyk rynkowych po stronie zakupowej (buy-side cases), mniej licznych i przykuwających uwagę od praktyk po stronie sprzedażowej (sell-side cases), za bezpośredni i równoległy do ochrony konsumentów cel prawa antytrustowego uznaje się wciąż ochronę małych dostawców przed eksploatacyjnymi praktykami dużych nabywców (na przykład narzucających zaniżone ceny zakupu $)^{9}$. Po drugie, niejako pośrednio MŚP są chronieni przed szkodzącymi im antykonkurencyjnymi praktykami, które jednocześnie godzą w interesy konsumentów. Zresztą, w wielu przypadkach ochrona tych ostatnich wymaga wręcz ochrony małych przedsiębiorców przed wykluczającymi praktykami ich większych rywali ${ }^{10}$. Wprawdzie w myśl słynnej paremii, uznawanej za centralne założenie czy wręcz aksjomat nie tylko amerykańskiego prawa antytrustowego, prawo antymonopolowe chroni konkurencję, nie zaś konkurentów ${ }^{11}$ — to znaczy, że konkurenci (także mali i średni) nie powinni być chronieni przed działaniami, które są kwintesencją konkurencji (takimi jak na przykład oferowanie tańszych lub bardziej innowacyjnych produktów), niemniej jednak w interesie zachowania tejże konkurencji poszczególni konkurenci, zwłaszcza mali i średni, mogą niekiedy wymagać szczególnej ochrony ${ }^{12}$. Wszak bez konkurentów nie może być konkurencji. Trudno też kwestionować poglądy aprobujące rolę prawa antymonopolowego w kreowaniu otoczenia sprzyjającego rozwojowi MŚP, zwłaszcza poprzez ochronę dwóch swobód o kardynalnym znaczeniu dla tej kategorii przedsiębiorców, to jest swobody przedsiębiorczości oraz swobody innowacji ${ }^{13}$. Współcześnie dominuje natomiast pogląd, że w prawie antymonopolowym należy unikać konstrukcji, które umożliwiają nieefektywnym przedsiębiorcom, niezależnie od ich wielkości, przetrwanie na rynku dzięki wyższym cenom lub niższej jakości oferowanych produktów - czyli kosztem konsumentów ${ }^{14}$. W konsekwencji odrzuca się też koncepcję utrzymywania w gospodarce dużej liczby małych, niekoniecznie efektywnych przedsiębiorców ${ }^{15}$. Wykorzystywanie prawa antymonopolowego dla ochrony MŚP przed wyzwaniami konkurencyjnymi ze strony ich większych konkurentów czy

9 J.B. Kirkwood, The Essence of Antitrust: Protecting Consumers and Small Suppliers from Anticompetitive Conduct, Fordham L.Rev. 81, 2013, s. 2433.

10 B. Baker, Exclusion as a Core Competition Concern, Antitrust L.J. 78, 2013, s. 527.

11 Źródłem tej sentencji jest wyrok SN USA w sprawie Brown Shoe C. v. United States.

12 W.J. Kolasky, What is competition? A comparison of U.S. and European perspectives, „Antitrust Bulletin” 49, 2004, s. 30.

13 A.M. Golodner, Antitrust, Innovation, Entrepreneurship and Small Business, „Small Business Economics" 16, 2001, s. 31.

14 L.A. Sullivan, W.S. Grimes, The Law of Antitrust: An Integrated Handbook, St. Paul 2000, s. 14; M. Motta, Competition Policy. Theory and Practice, Cambridge 2004, s. 25.

15 F.S. McChesney, Talking 'Bout My Antitrust Generation: Competition For and In the Field of Competition Law, Emory L.J. 52, 2003, s. 1407. 
kontrahentów jest — w świetle tych poglądów — nie tylko nieefektywne, ale oznacza jaskrawą protekcję interesów MŚP wbrew podstawowym zasadom, na jakich opiera się prawo antymonopolowe - zwłaszcza że są oni nie mniej skłonni do naruszania reguł konkurencji (na przykład angażując się w praktyki kartelowe) niż przedsiębiorcy duzi ${ }^{16}$.

\section{Specyfika definicji MŚP w prawie antymonopolowym}

Specyficzne regulacje odnoszące się wprost do MŚP nie są często spotykane w prawie antymonopolowym. Jeszcze rzadziej formułuje ono szczególne definicje tej kategorii przedsiębiorców. Stosowanie regulacji antymonopolowych wobec MŚP komplikuje dodatkowo fakt, że tylko w ograniczonym stopniu mogą być tu użyteczne definicje tego pojęcia wypracowane na gruncie innych dziedzin prawa (na przykład prawa pomocy publicznej), ponieważ kryteria stosowane w tych definicjach są często mało adekwatne z perspektywy prawa antymonopolowego. O ile na przykład standardowy wskaźnik rocznego obrotu przedsiębiorcy może niekiedy stanowić pewną wskazówkę co do jego pozycji rynkowej, o tyle już liczba zatrudnionych może nie znaczyć nic w tym kontekście. Z tego też powodu kwalifikacja adresatów prawa antymonopolowego jako MŚP nie powinna się opierać na kryteriach bezwzględnej wielkości, ale takich, które uwzględniają relację do innych przedsiębiorców działających na danym rynku właściwym. Decydującym czynnikiem jest tu struktura tegoż rynku ${ }^{17}$. Względną pozycję rynkową przedsiębiorcy mierzy się na podstawie oceny wielorakich parametrów rynku właściwego, w tym zwłaszcza udziału w nim danego przedsiębiorcy. Ponieważ w praktyce przedsięwzięcie to może być nader skomplikowane, czasami dopuszcza się (na przykład w Niemczech) sięganie, dla wstępnej orientacji, do kryteriów stosowanych w procedurze kontroli koncentracji, to jest wartości obrotów ${ }^{18}$. W każdym razie może się okazać, że pomimo stosunkowo dużego obrotu, przedsiębiorca będzie sklasyfikowany jako mały lub średni, dlatego że jest aktywny na rynku, na którym kilku innych konkurentów wykazuje znacznie wyższe obroty. Jednakże na innym rynku przedsiębiorca mający analogiczny obrót może być już uznany za dużego przedsiębiorcę — w relacji do konkurentów obecnych na tym rynku.

16 R.A. Posner, Antitrust Law, Chicago 2001, s. 26.

17 General Cartel Bans: Criteria for Exemption for Small and Medium-sized Enterprises, OECD 1996, s. 7; M. Carpagnano, International Report, [w:] Antitrust for Small and Middle Size Undertakings and Image Protection from Non-Competitors, red. P. Këllezi, B. Kilpatrick, P. Kobel, Berlin 2014, s. 8.

18 M. Carpagnano, op. cit., s. 9. 


\section{Prawo antymonopolowe jako determinant rozwoju MŚP}

Wpływ prawa antymonopolowego na rozwój MŚP można rozpatrywać w różnych kontekstach, w tym z perspektywy publicznego i prywatnego egzekwowania tego prawa, uwzględniając dodatkowo dwoistą sytuację MŚP jako podmiotów poszkodowanych jego naruszeniami (to jest jego beneficjentów), a także jako adresatów zakazów i nakazów antymonopolowych (to jest naruszycieli reguł konkurencji).

W podstawowym kontekście publicznoprawnym funkcjonowanie odpowiedniej infrastruktury prawnej i instytucjonalnej chroniącej (w interesie publicznym) konkurencję rynkową (jako dobro publiczne) odgrywa niepodważalną rolę w zapewnieniu równych szans rozwoju MŚP. Przede wszystkim dlatego, że pozwala przeciwdziałać tworzeniu przez dużych przedsiębiorców sztucznych barier wejścia na rynek, umożliwiając tym samym MŚP realne korzystanie z wolności konkurowania. Ci ostatni są szczególnie podatni na naruszenia reguł konkurencji przez dużych przedsiębiorców, często dominantów rynkowych, występując nie tylko w roli konkurentów, ale także kontrahentów, to jest nabywców, a nawet dostawców. Przykładowo, zmowy kartelowe dużych wytwórców surowców mogą niekorzystnie rzutować na ceny lub dostawy środków produkcji wykorzystywanych przez MŚP. Duzi przedsiębiorcy, dysponujący znacznymi zasobami, mogą też na przykład stosować tak zwane drapieżne praktyki cenowe, zaniżając ceny z zamiarem ograniczenia zdolności konkurencyjnych ich mniejszych konkurentów.

W większości krajów prawo antymonopolowe nie zawiera jednak specyficznych rozwiązań różnicujących zakres jego ochrony ze względu na wielkość przedsiębiorców narażonych na delikty antykonkurencyjne. Najbardziej znanym spośród nielicznych wyjątków od tej normy spotykanych w krajach wysokorozwiniętych są specyficzne rozwiązania przewidziane w prawie antymonopolowym RFN obejmujące specjalną ochroną MŚP przed nadużywaniem przewagi przez ich większych kontrahentów lub konkurentów niebędących wprawdzie dominantami, ale dysponujących „relatywną władzą rynkową” lub „przewagą rynkową"19. Celem tych regulacji o silnie ordoliberalnej proweniencji jest ochrona małych i średnich dostawców lub nabywców określonych produktów przed dyskryminacyjnymi praktykami kontrahentów, od których są zależni, jak również ochrona małych i średnich konkurentów przed wykluczającymi praktykami ich silniejszych rywali (na przykład sztucznym zaniżaniem cen). Nawiasem mówiąc, prominentni przedstawiciele niemieckiej doktryny podnoszą ostatnio, że w epoce gospodarki cyfro-

19 Zob. § 20 ust. 1 i 3 ustawy z 1957 roku o zapobieganiu ograniczeniom konkurencji (Gesetz gegen Wettbewerbsbeschränkungen, GWB); M. Roszak, B. Turno, Przewaga kontraktowa dostawców lub nabywców towarów i jej nieuczciwe wykorzystywanie w regulacjach niemieckich i francuskich - wskazówki dla polskiej praktyki i ustawodawcy?, „Internetowy Kwartalnik Antymonopolowy i Regulacyjny" 2017, nr 8 (6), s. 18. 
wej ograniczanie zakresu ochrony przed nadużywaniem „relatywnej władzy rynkowej" tylko do MŚP jest nieuzasadnione, postulując zniesienie tego ograniczenia w ramach planowanej dziesiątej nowelizacji GWB ${ }^{20}$. Jednocześnie zalecają bardziej elastyczne niż dotąd stosowanie zakazu nadużywania „,przewagi rynkowej”, tak aby skuteczniej chronić zwłaszcza innowacyjnych MŚP przed defensywnymi, wykluczającymi praktykami ich silniejszych konkurentów ${ }^{21}$.

Znamienne, że podyktowane względami redystrybucyjnymi rozwiązania obejmujące MŚP wprost i bezpośrednio nadzwyczajną ochroną antymonopolową są zazwyczaj wprowadzane w krajach często rozwijających się, które stosunkowo niedawno implementowały prawo antymonopolowe, $\mathrm{z}$ dystansem podchodząc do paradygmatów wykształconych w najbardziej zaawansowanych systemach ochrony konkurencji, co thumaczy się specyficznymi uwarunkowaniami społeczno-gospodarczymi i kulturowymi tych krajów. Modelowym przykładem takiego podejścia jest ostatnia radykalna nowelizacja prawa antymonopolowego w RPA, która wydatnie wzmacnia ochronę tamtejszych MŚP poprzez między innymi rozszerzenie katalogu godzących w nie dyskryminacyjnych praktyk nadużywania pozycji dominującej, wprowadzenie obowiązkowej analizy wpływu notyfikowanych koncentracji na sytuację rynkową MŚP (w ramach badania przesłanki interesu publicznego), upoważnienie właściwego ministra do zaskarżania w interesie MŚP decyzji w sprawach koncentracji oraz umożliwienie nakładania podwyższonych kar za naruszenia reguł konkurencji godzące w MŚP22.

Wprawdzie prawo antymonopolowe sprzyja rozwojowi MŚP, chroniąc ich zdolności gospodarcze, niemniej jednak bywa też przez nich postrzegane jako broń obosieczna, i zgoła wręcz kontestowane. Poza wyrażanym czasem sceptycyzmem w kwestii zdolności władz antymonopolowych do skutecznej obrony MŚP przed nadużyciami innych, zwykle większych przedsiębiorców, ci pierwsi muszą się liczyć także z rygorami prawa antymonopolowego, ponieważ podlegają im zasadniczo na równi z innymi przedsiębiorcami. W niektórych krajach, obwieszczając désintéressement odnośnie do protekcjonalnego traktowania MŚP na gruncie prawa antymonopolowego, jak mantrę powtarza się przywoływany już slogan, iż prawo to ma chronić konkurencję a nie konkurentów (rozczarowanych konkurencją). Podobny wydźwięk mają deklaracje o braku „bezkrytycznego sentymentalizmu" wobec MŚP w procesie wdrażania prawa antymonopolowego ${ }^{23}$. Wszelako nie da się zaprzeczyć, że powszechnie, jeśli nie we wszystkich syste-

${ }^{20}$ H. Schweitzer et al., Modernising the Law on Abuse of Market Power: Report for the Federal Ministry for Economic Affairs and Energy (Germany), s. 2, https://ssrn.com/abstract=3250742 (dostęp: 17.09.2018).

21 Ibidem, s. 7.

22 J. Oxenham, M.J. Currie, A. Stargard, Changing South Africa's Competition Law Regime: A Populist Departure from International Best Practices, J. European Competition Law \& Practice 10, 2019, s. 232.

23 D. Bailey, United Kingdom, [w:] Antitrust for Small and Middle Size Undertakings..., s. 242. 
mach ochrony konkurencji, ta kategoria adresatów prawa antymonopolowego jest głównym, choć zwykle nienazwanym, beneficjentem tak zwanych bezpiecznych przystani (safe harbours), to jest wyłączeń spod reżimu tego prawa, które często uwzględniają, aczkolwiek nie bezpośrednio, wielkość objętych nimi przedsiębiorców, operując na przykład kryterium ich udziału w rynku. Zastrzec przy tym należy, że w przypadku regulacji wyłączających (w różnym stopniu) niektóre sektory czy branże gospodarki z zakresu obowiązywania prawa antymonopolowego (na przykład sektor rolny w UE), na preferencyjne traktowanie wynikające $\mathrm{z}$ takich derogacji mogą liczyć także duzi przedsiębiorcy. Kryterium pozycji rynkowej adresatów komentowanych wyłączeń pojawia się już natomiast standardowo w wyłączeniach spod zakazu porozumień ograniczających konkurencję, obejmujących tak zwane porozumienia bagatelne (de minimis), jak również porozumienia prorozwojowe, objęte wyłączeniami grupowymi na podstawie reguły rozsądku. Celem tych specyficznych regulacji jest umożliwienie przedsiębiorcom, zwłaszcza MŚP, które w olbrzymiej większości przypadków nie przekraczają ustanowionych progów udziału w rynku, bezpiecznego podejmowania korzystnej dla nich współpracy, pod warunkiem respektowania jej dozwolonych granic, to jest „czerwonych linii”, które konstytuują bezwzględnie zakazane ograniczenia konkurencji (hard-core restrictions).

W niektórych krajach preferencyjne wyłączenia spod ogólnych reguł konkurencji adresowane są explicite $\mathrm{i}$ - w zasadzie - wyłącznie do MŚP. Ponownie instruktywny przykład tego rodzaju rozwiązań oferuje niemieckie prawo antymonopolowe. Umożliwia ono wprost konkurującym przedsiębiorcom zawieranie porozumień kooperacyjnych (Mittelstandskartelle) służących racjonalizacji aktywności gospodarczej, pod warunkiem że nie będą one miały znacznego wpływu na konkurencję oraz będą się przyczyniały do zwiększenia konkurencyjności MŚP ${ }^{24}$. Konstrukcja tych karteli opiera się na idei „strukturalnego zrównywania”, mającego ułatwiać słabszym konkurentom nadrabianie konkurencyjnych przewag ich dużych rywali, a przez to poprawiać strukturalny wymiar konkurencji ${ }^{25}$. Przedmiotem dopuszczalnej współpracy może być na przykład działalność produkcyjna, badawczo-rozwojowa, finansowa, reklamowa czy dystrybucyjna. W praktyce dominującą formą tej współpracy jest tworzenie przez MŚP wspólnych agencji sprzedaży, co jest najprostszym sposobem osiągania efektów ekonomii skali, niezależnie od wielkości przedsiębiorcy. Odnośnym wyłączeniem nie jest natomiast objęta współpraca niezorientowana bezpośrednio na promowanie efektywności, a mająca raczej eliminować konkurencję (na przykład zwykłe uzgadnianie cen).

Przykładem skrajnie już posuniętej protekcji MŚP jest generalne i blankietowe ich wyłączenie spod obowiązywania prawa antymonopolowego w Indonezji, uzasadniane ich nieprzyjaznym otoczeniem biznesowym ${ }^{26}$. Rozwiązanie to jest

\footnotetext{
$24 \S 3$ GWB.

25 General Cartel Bans..., s. 11.

26 E.M. Fox, op. cit., s. 579.
} 
wysoce problematyczne, paradoksalnie także z perspektywy jego beneficjentów, skoro pozbawia ich ochrony w przypadku - możliwych przecież - antykonkurencyjnych nadużyć ze strony innych MŚP.

Odnosząc się krótko do wpływu prywatnego egzekwowania prawa antymonopolowego na rozwój MŚP, podnieść należy wstępnie, że o ile wszystkie ofiary naruszeń tego prawa muszą liczyć się z poważnymi trudnościami w dochodzeniu roszczeń z tego tytułu, o tyle obciążenia te są szczególnie dotkliwe dla MŚP, głównie za sprawą ich ograniczonych zasobów. Dzieje się tak na przykład w większości krajów europejskich, nie wyłączając RP, gdzie prywatny tryb egzekwowania prawa antymonopolowego przed sądami powszechnymi wciąż jest obarczony poważnymi dysfunkcjami i pozostaje w stanie inercji ${ }^{27}$. Co więcej, z reguły nie uwzględnia on faktycznej asymetrii pomiędzy małymi i średnimi a dużymi przedsiębiorcami w dostępie do informacji. Aby zaradzić temu problemowi, postuluje się szereg rozwiązań mających ułatwić dochodzenie roszczeń przez MŚP, w tym wprowadzenie „szybkiej ścieżki” dla postępowań z ich powództwa; zmniejszenie obciążeń finansowych i organizacyjnych towarzyszących tym postępowaniom czy też ustanowienie wzruszalnych domniemań prawnych dotyczących szkód wyrządzonych naruszeniem reguł konkurencji. Przykładem już wdrożonego, a przy tym wysoce kontrowersyjnego przywileju procesowego przyznanego MŚP jest przyjęte w prawie konkurencji UE i jej państw członkowskich ograniczenie solidarnej odpowiedzialności MŚP za szkodę wyrządzoną naruszeniem reguł konkurencji ${ }^{28}$.

\section{Uwagi końcowe}

W teorii i z założenia, prawo antymonopolowe i polityka wspierania rozwoju MŚP powinny ze sobą współgrać, jednak nie zawsze tak się dzieje. Jak dotąd nie wypracowano jakiegoś idealnego i uniwersalnego modelu powiązania misji ochro-

27 Zob. R. Stefanicki, Prywatnoprawne środki dochodzenia roszczeń z tytułu naruszenia regut konkurencji, Warszawa 2014; K. Kohutek, Szkoda antymonopolowa. Zasady odpowiedzialności oraz dochodzenia roszczeń odszkodowawczych, Warszawa 2018; R. Molski, Dysfunkcje prawa antymonopolowego, [w:] Dysfunkcje publicznego prawa gospodarczego, red. M. Zdyb, E. Kruk, G. Lubeńczuk, Warszawa 2018, s. 263.

28 Zob. art. 11 ust. 2 dyrektywy Parlamentu Europejskiego i Rady 2014/104/UE z dnia 26 listopada 2014 roku w sprawie niektórych przepisów regulujących dochodzenie roszczeń odszkodowawczych z tytułu naruszenia prawa konkurencji państw członkowskich i UE, objęte przepisami prawa krajowego, Dz.Urz. UE L 349 z 5.12.2014, s. 1; art. 5 ustawy z 2017 roku o roszczeniach o naprawienie szkody wyrządzonej przez naruszenie prawa konkurencji, Dz.U. z 2017 r. poz. 1132; A. JurkowskaGomułka, How to Throw the Baby Out with the Bath Water. A Few Remarks on the Currently Accepted Scope of Civil Liability for Antitrust Damages, „Yearbook of Antitrust and Regulatory Studies” 8, 2015, nr 12, s. 66; P. Podrecki, K. Wiese, Solidarna odpowiedzialność podmiotów naruszajacych reguty konkurencji i jej ograniczenia, [w:] Dochodzenie przed sądem polskim roszczeń odszkodowawczych z tytułu naruszenia reguł konkurencji, red. A. Piszcz, D. Wolski, Warszawa 2016, s. 124. 
ny konkurencji, jaką ma do wypełnienia prawo antymonopolowe, z potrzebą wspierania rozwoju MŚP. I nie wydaje się, aby to było możliwe. Nawiązując do motta przewodniego niniejszego artykułu, zgodzić się jednak można ze stanowiskiem, że prawo antymonopolowe nie powinno w wyjątkowy sposób chronić przedsiębiorców tylko dlatego, że są mali i nie są w stanie sprostać konkurencji ze strony większych rywali, zwłaszcza jeśli miałoby się to odbywać kosztem konsumentów.

\section{Bibliografia}

Bailey D., United Kingdom, [w:] Antitrust for Small and Middle Size Undertakings and Image Protection from Non-Competitors, red. P. Këllezi, B. Kilpatrick, P. Kobel, Berlin 2014.

Baker B., Exclusion as a Core Competition Concern, „Antitrust Law Journal” 78, 2013.

Carpagnano M., International Report, [w:] Antitrust for Small and Middle Size Undertakings and Image Protection from Non-Competitors, red. P. Këllezi, B. Kilpatrick, P. Kobel, Berlin 2014.

Cicero M.T., De Finibus Bonorum et Malorum, Oxford 1998.

European Competition Law Annual 1997: The Objectives of Competition Policy, red. C.D. Ehlermann, L.L. Laudati, Oxford 1998.

Fox E.M., Equality, Discrimination, and Competition Law: Lessons from and for South Africa and Indonesia, „Harvard International Law Journal” 41, 2000.

General Cartel Bans: Criteria for Exemption for Small and Medium-sized Enterprises, OECD 1996.

The Goals of Competition Law, red. D. Zimmer, Cheltenham 2012.

Golodner A.M., Antitrust, Innovation, Entrepreneurship and Small Business, „Small Business Economics" 16, 2001.

Hovenkamp H., Federal Antitrust Policy: The Law of Competition and Its Practice, St. Paul 1999.

Hovenkamp H., Whatever Did Happen to the Antitrust Movement?, „Notre Dame Law Review” 94, 2019.

Jurkowska-Gomułka A., How to Throw the Baby Out with the Bath Water. A Few Remarks on the Currently Accepted Scope of Civil Liability for Antitrust Damages, „Yearbook of Antitrust and Regulatory Studies" 8, 2015, nr 12.

Kirkwood J.B., The Essence of Antitrust: Protecting Consumers and Small Suppliers from Anticompetitive Conduct, „Fordham Law Review” 81, 2013.

Kohutek K., Szkoda antymonopolowa. Zasady odpowiedzialności oraz dochodzenia roszczeń odszkodowawczych, Warszawa 2018.

Kolasky W.J., What is competition? A comparison of U.S. and European perspectives, „Antitrust Bulletin" 49, 2004.

McChesney F.S., Talking 'Bout My Antitrust Generation: Competition For and In the Field of Competition Law, „Emory Law Journal” 52, 2003.

Molski R., Dysfunkcje prawa antymonopolowego, [w:] Dysfunkcje publicznego prawa gospodarczego, red. M. Zdyb, E. Kruk, G. Lubeńczuk, Warszawa 2018.

Molski R., Prawo antymonopolowe w obliczu globalizacji. Kierunki rozwoju, Szczecin-Bydgoszcz 2007.

Motta M., Competition Policy. Theory and Practice, Cambridge 2004.

Oxenham J., Currie M.J., Stargard A., Changing South Africa's Competition Law Regime: A Populist Departure from International Best Practices, „Journal of European Competition Law \& Practice" 10, 2019.

Prawo 329, 2020

(C) for this edition by CNS 
Parret L., Shouldn't We Know What We Are Protecting? Yes We Should! A Plea for a Solid and Comprehensive Debate About the Objectives of EU Competition Law and Policy, „European Competition Journal" 6, 2010.

Podrecki P., Wiese K., Solidarna odpowiedzialność podmiotów naruszających reguły konkurencji i jej ograniczenia, [w:] Dochodzenie przed sądem polskim roszczeń odszkodowawczych z tytutu naruszenia regut konkurencji, red. A. Piszcz, D. Wolski, Warszawa 2016.

Posner R.A., Antitrust Law, Chicago 2001.

Roszak M., Turno B., Przewaga kontraktowa dostawców lub nabywców towarów i jej nieuczciwe wykorzystywanie w regulacjach niemieckich i francuskich — wskazówki dla polskiej praktyki i ustawodawcy?, „Internetowy Kwartalnik Antymonopolowy i Regulacyjny” 2017, nr 8 (6).

Schumacher E.F., Małe jest piękne. Ekonomia z założeniem, że człowiek się liczy, Warszawa 2013.

Schweitzer H., Haucap J., Kerber W., Welker R., Modernising the Law on Abuse of Market Power: Report for the Federal Ministry for Economic Affairs and Energy (Germany), https://ssrn.com/ abstract $=3250742$ (dostęp: 17.09.2018).

Stefanicki R., Prywatnoprawne środki dochodzenia roszczeń z tytułu naruszenia reguł konkurencji, Warszawa 2014.

Sullivan L.A., Grimes W.S., The Law of Antitrust: An Integrated Handbook, St. Paul 2000.

Trebilcock M., Winter R.A., Collins P., Iacobucci E.M., The Law and Economics of Canadian Competition Policy, Toronto 2002.

Vaheesan S., The Evolving Populisms of Antitrust, „Nebraska Law Review” 93, 2014.

Wright J.D., Dorsey E., Klick J., Rybnicek J.M., Requiem for a Paradox: The Dubious Rise and Inevitable Fall of Hipster Antitrust, „Arizona State Law Journal” 51, 2019.

\title{
Antitrust law and the policy of supporting the development of small and medium enterprises
}

\author{
Summary
}

The aim of the article is to deepen the still insufficient scientific reflection on the role of antitrust law in the policy of supporting the development of small and medium-sized enterprises (SMEs). Firstly, a synthetic picture of the evolution and current state of views on the issue of protecting SMEs as an objective of antitrust law was depicted. Then, the specificity of the SME definition in antitrust law is presented. The next part of the article is devoted to the impact of antitrust law on the development of SMEs, considered from the perspective of public and private enforcement of this law, and taking into account the dual situation of SMEs as its beneficiaries and infringers. The summary indicates that although antitrust law and policies to support the development of SMEs should work together, this is not always the case. The position that antitrust law should not protect entrepreneurs in a unique way just because they are small and unable to cope with competition from larger rivals, especially if it would be at the expense of consumers, was deemed worthy of recognition.

Keywords: antitrust law, small and medium enterprises, economic policy. 